\title{
Morphology of the Lingual Papillae of the Japanese lesser flying squirrel and four-toed hedgehog
}

\author{
By
}

\author{
Shoichi EMURA \\ Heisei College of Health Sciences, Gifu-shi, Gifu 501-1131, Japan
}

-Received for Publication, February 28, 2019-

Key Words: Japanese lesser flying squirrel, four-toed hedgehog, lingual papillae, SEM

\begin{abstract}
Summary: Author examined the dorsal lingual surfaces of the adult Japanese lesser flying squirrel (Pteromys momonga) and four-toed hedgehog (Atelerix albiventris) by scanning electron microscopy. In the Japanese lesser flying squirrel, the filiform papilla of the lingual body consisted of a large conical papilla. The filiform papilla of the lingual prominence was spoon in shape. The fungiform papillae were round in shape and scattered among the filiform papillae. Many foliate papillae were observed on the posterolateral regions of the lingual body. The foliate papillae had some ridges separated by deep grooves. The vallate papilla was located between lingual body and root. Several long conical papillae derived from the posterolateral margin of the tongue. In the four-toed hedgehog, the filiform papilla of the lingual apex had a conical process. The filiform papilla of the lingual body had some processes. The fungiform papillae were round in shape. The foliate papillae were observed on the posterolateral regions of the lingual body. The papilla was separated from each other by a furrow. The vallate papilla consisted of a central papilla and an annular pad. These findings suggest that in the structure of the lingual papillae of the Japanese lesser flying squirrel there is similar to that of the sugar glider and the lingual papillae of the four-toed hedgehog is different from that of the Japanese lesser flying squirrel.
\end{abstract}

Many studies have been published on the structures of the lingual surfaces in various animals. In the order Rodentia, there have been many scanning electron microscopic (SEM) studies of the tongues of rat (Iwasaki et al., 1997), mouse (Iwasaki et al., 1985), guinea pig (Iwasaki and Miyata, 1985), flying squirrel (Emura et al., 1999), nutria (Emura et al., 2001), rabbit (Silva et al., 2002), black-tailed prairie dog (Emura, 2008a), capybara (Emura, 2008b) and Patagonian cavy (Emura et al., 2011). In the order Eulipotyphla, there has been a SEM study of the tongue of long-eared hedgehog (Parchami et al., 2018). Such studies reveal variations in morphology and distribution of papillae on the dorsal lingual surface among animal species.

However, no SEM study on the tongues of the Japanese lesser flying squirrel and four-toed hedgehog has been carried out. This study three-dimensionally examined the dorsal lingual surfaces of the Japanese lesser flying squirrel and four-toed hedgehog, in order to compare results with those from previous reports on other mammals.

\section{Materials and Methods}

The tongues of the adult Japanese lesser flying squirrel (Pteromys momonga) of the family Sciurinae and fourtoed hedgehog (Atelerix albiventris) of the family Erinaceidae were used in this study. The tongues were fixed in $10 \%$ formalin. Small blocks containing papillae were cut with a razor blade, post-fixed with $1 \%$ osmium tetroxide for $1 \mathrm{~h}$. Thereafter, the specimens were dehydrated through a graded series of acetone and critical-point-dried. All specimens were sputtered with Pt-Pd before being examined under SEM (Hitachi S-3000N, Tokyo, Japan) at an accelerating voltage of $10 \mathrm{kV}$.

\section{Results}

Japanese lesser flying squirrel

Macroscopically, the tongue of the Japanese lesser flying squirrel was about $2.3 \mathrm{~cm}$ long and the lingual body had lingual prominence on the posterior part (Fig. 1). Three vallate papillae arranged in an inverted V-shape were observed on the dorsum. 


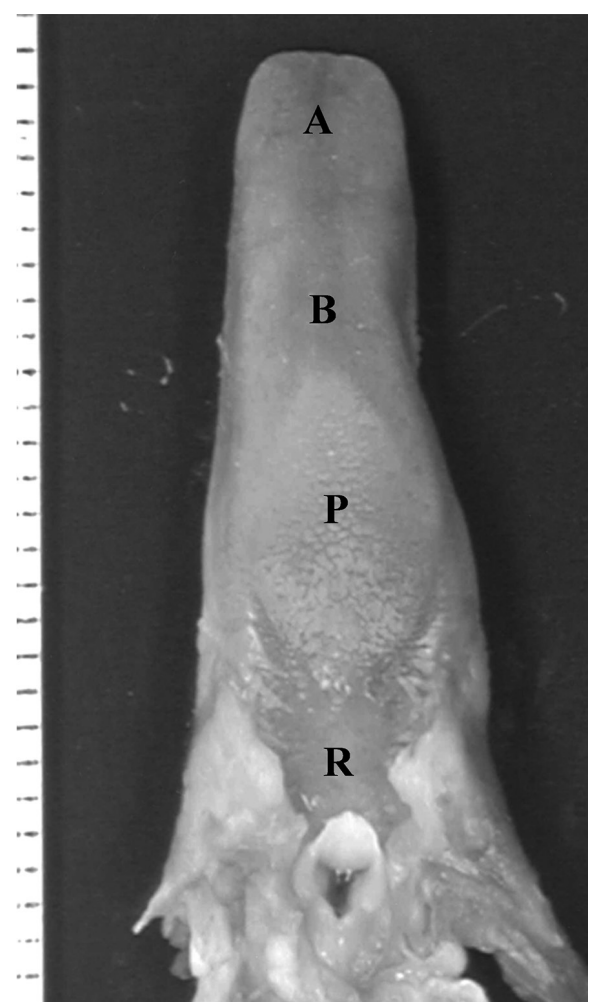

Fig. 1. Macrograph of Japanese lesser flying squirrel tongue. $\mathrm{A}=$ lingual apex. $\mathrm{B}=$ lingual body. $\mathrm{P}=$ lingual prominence. $\mathrm{R}=$ lingual root.
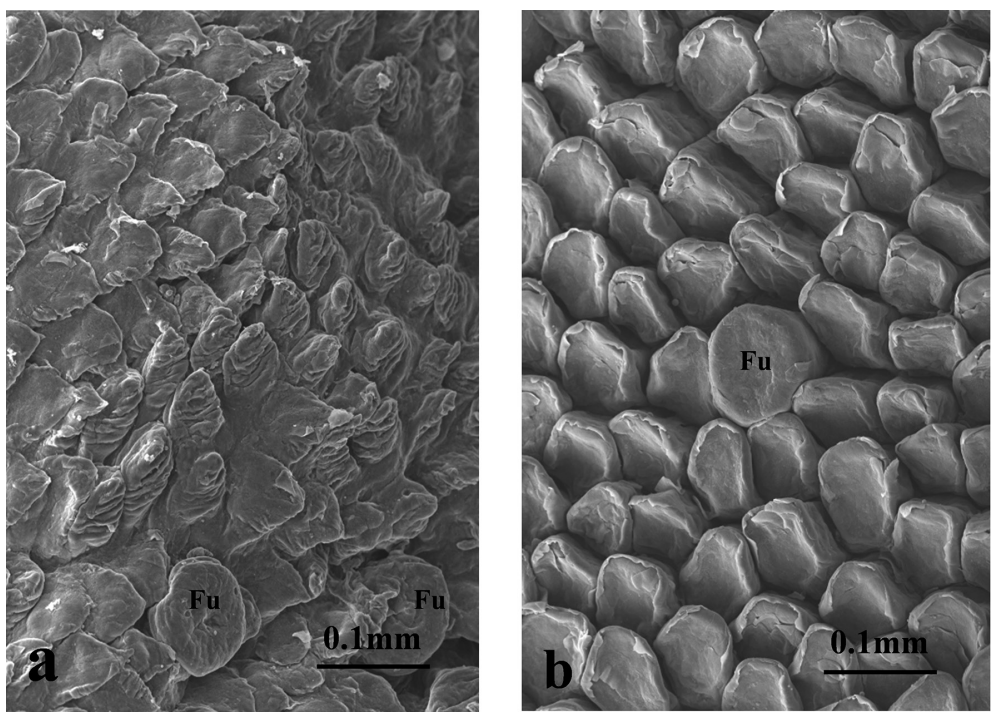

Fig. 2. SEM micrographs of B in Fig. 1. (a) The filiform papilla consists of a large conical papilla. (b) The filiform papilla of the lingual prominence is spoon in shape. $(\mathrm{a}, \mathrm{b})$ The fungiform papillae (Fu) are round in shape.
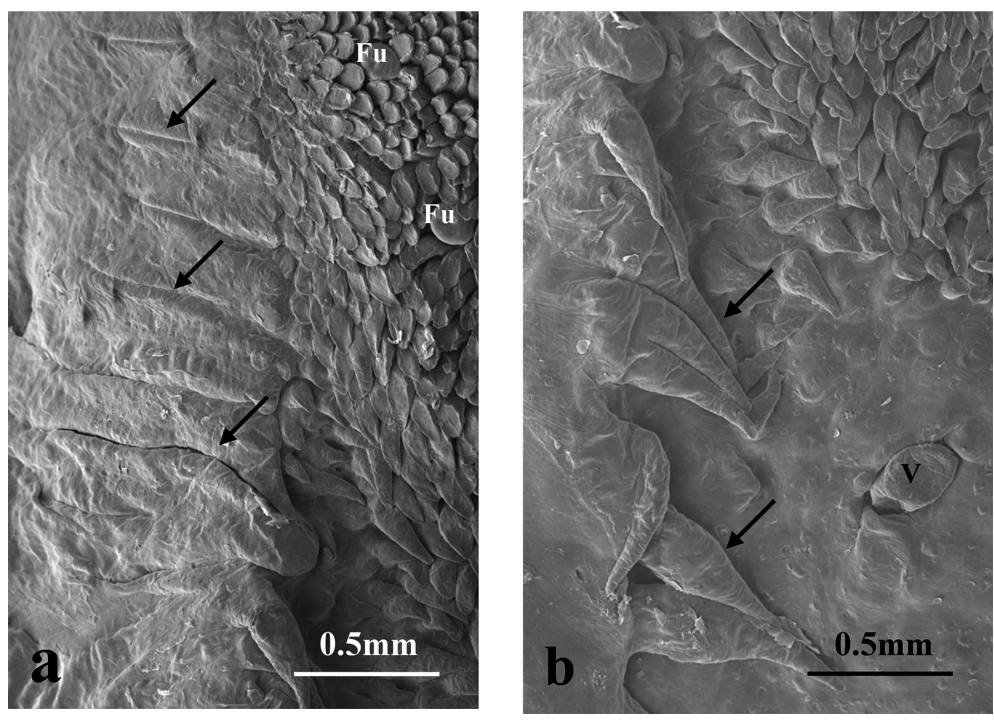

Fig. 3. SEM micrographs of the posterolateral regions. (a) Note many foliate papillae. The foliate papillae have some ridges separated by deep grooves (arrows). (b) The vallate papilla (V) is located between lingual body and root. Several long conical papillae (arrows) derive from the posterolateral margin of the tongue. $\mathrm{Fu}=$ fungiform papillae.
The filiform papilla of the lingual body consisted of a large conical papilla (Fig. 2a). The filiform papilla of the lingual prominence was spoon in shape (Fig. 2b). The fungiform papillae were round in shape and scattered among the filiform papillae (Fig. 2a, b). Many foliate papillae were observed on the posterolateral regions of the lingual body (Fig. 3a). The foliate papillae had some ridges separated by deep grooves (Fig. 3a). The vallate papilla was located between lingual body and root (Fig. $3 b)$. Several long conical papillae derived from the posterolateral margin of the tongue (Fig. 3b). 


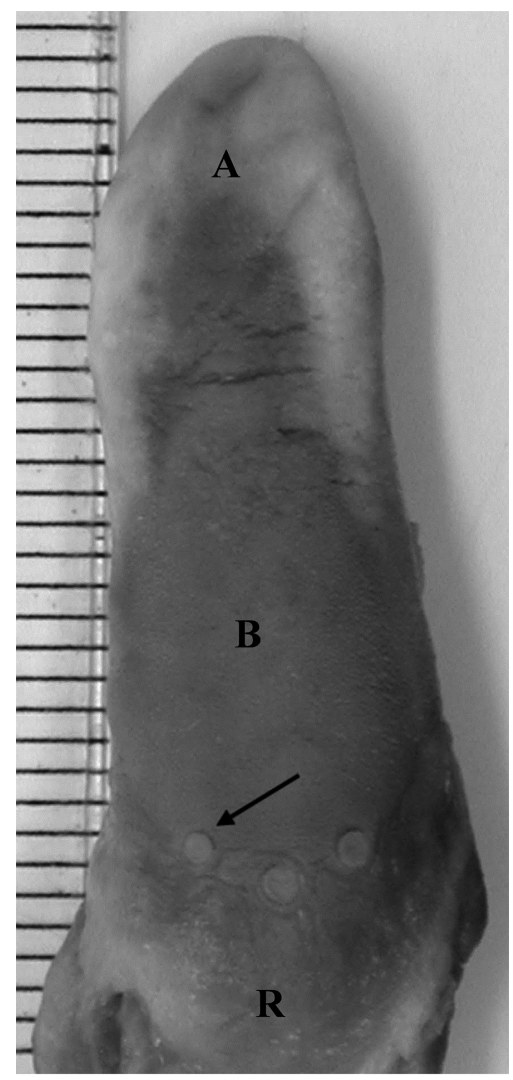

Fig. 4. Macrograph of the four-toed hedgehog tongue. Three vallate papillae (arrow) arranged in an inverted V-shape are observed on the dorsum. $\mathrm{A}=$ lingual apex. $\mathrm{B}=$ lingual body. $\mathrm{R}=$ lingual root.
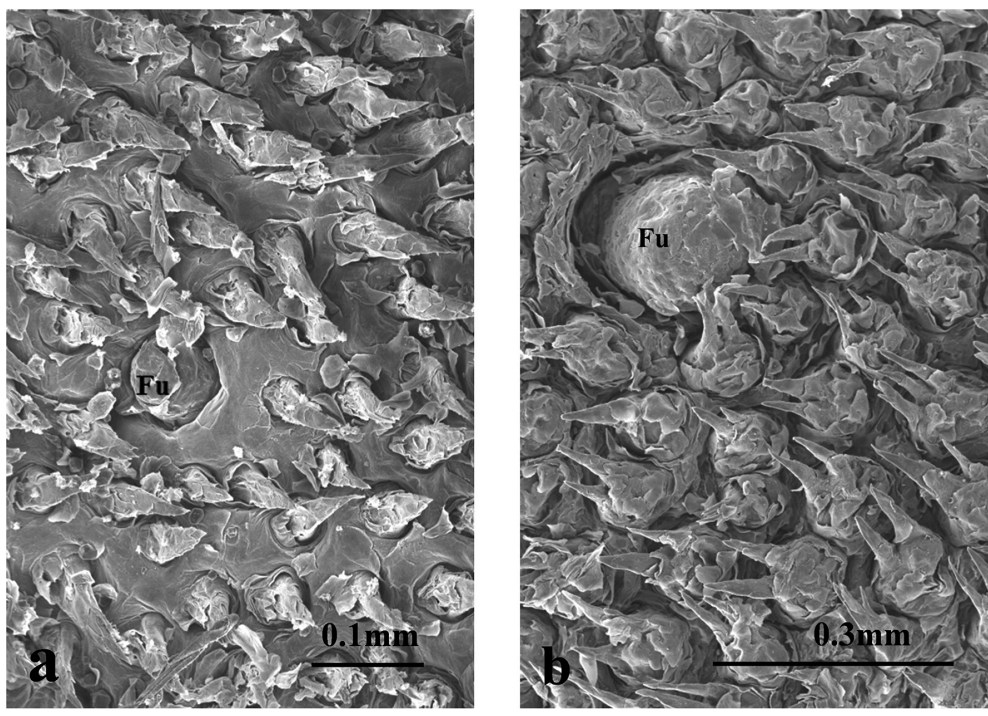

Fig. 5. SEM micrographs of A and B in Fig. 1. (a) The filiform papilla of the lingual apex has a conical process. (b) The filiform papilla of the lingual body has some processes. $(\mathrm{a}, \mathrm{b})$ The fungiform papillae $(\mathrm{Fu})$ are round in shape.
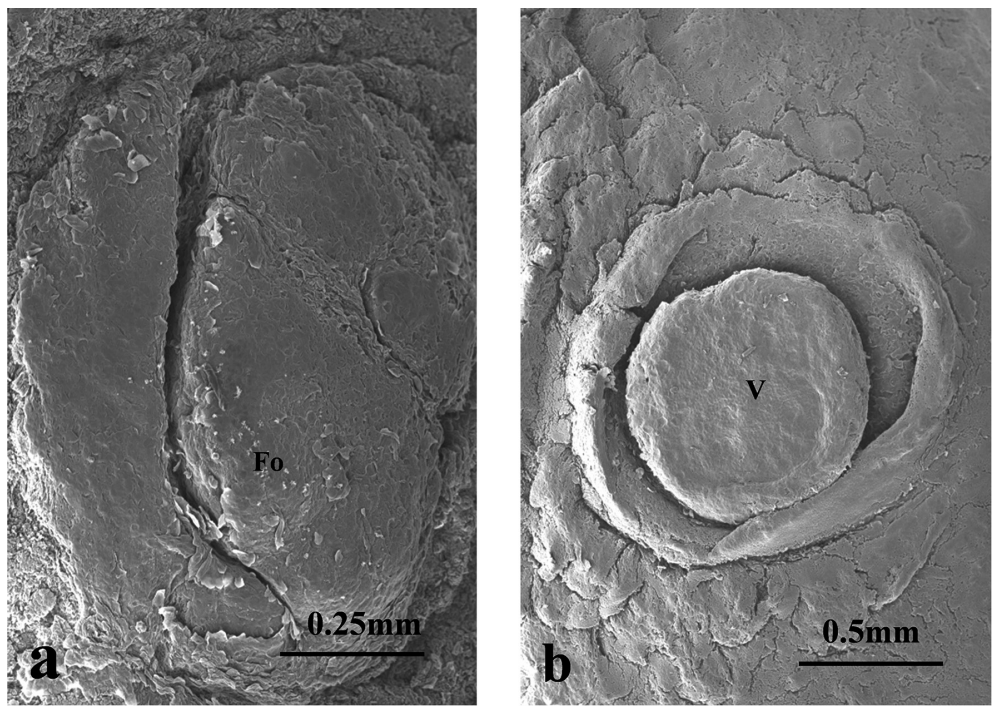

Fig. 6. SEM micrographs of the foliate and vallate papillae. (a) The foliate papilla (Fo) is separated from each other by a furrow. The vallate papilla (V) consists of a central papilla and an annular pad.

\section{Four-toed hedgehog}

Macroscopically, the tongue of the four-toed hedgehog was about $3.5 \mathrm{~cm}$ long and the lingual body had no lingual prominence on the posterior part (Fig. 4). Three vallate papillae arranged in an inverted $\mathrm{V}$-shape were observed on the dorsum (Fig. 4). The filiform papilla of the lingual apex had a conical process (Fig. 5a). The filiform papilla of the lingual body had some processes (Fig. 5b). The fungiform papillae were round in shape scattered among the filiform papillae (Fig. 5a, b). The foliate papillae were observed on the posterolateral regions of the lingual body (Fig. 6a). The papilla was separated from each other by a furrow (Fig. 6a). The vallate papilla consisted of a central papilla and an annular pad (Fig. 6b). 


\section{Discussion}

Many SEM studies of the lingual papillae have been carried out in the order rodentia. In lingual surface of the guinea pig, the filiform papillae consisted of a larger main papilla and two secondary papillae (Iwasaki and Miyata, 1985). In the flying squirrel (Emura et al., 1999), nutria (Emura et al., 2001) and capybara (Emura, 2008b), the secondary papillae like the filiform papillae of the guinea pig were not observed. The filiform papilla of the Patagonian cavy (Emura et al., 2011) was similar to those of the flying squirrel, nutria and capybara. The filiform papillae of the lingual body in the Japanese lesser flying squirrel consist of a large conical papilla. In the flying squirrel and nutria, the fungiform papillae were dome-shape and scattered among the filiform papillae (Emura et al., 1999; Emura et al., 2001). However, there were no fungiform papillae in the lingual dorsal surfaces of the Patagonian cavy and capybara, but were observed in both lateral sides of the tongues (Emura et al., 2011; Emura, 2008b). In this study, the fungiform papillae of the Japanese lesser flying squirrel are scattered among the filiform papillae of the lingual dorsal surface. Therefore, the distribution region of the fungiform is different from those of the Patagonian cavy and capybara. The foliate papillae are well developed in the order Rodentia. My observation in the Japanese lesser flying squirrel is well developed and shows the morphological characteristic for this type of papilla. In the bush-tailed rat kangaroo (Emura et al., 1999), several long conical papillae derived from the posterolateral margin of the tongue where the foliate papillae had been shown to be distributed in many other animal species. In this study, several long conical papillae derive from the posterolateral margin of the tongue. In the long-eared hedgehog, the filiform papilla covering the body of the tongue had an apparent fork-like appearance (Prchami et al., 2018). The foliate papillae were situated on both lateral root medial to the huge lateral lingual folds as three large obliquely situated parallel folds (Prchami et al., 2018). In the fourtoed hedgehog, the filiform papilla of the lingual body has some processes. The foliate papillae are observed on the posterolateral regions of the lingual body and a papilla is separated from each other by a furrow. The structure of the foliate papillae in the four-toed hedgehog is different from those of the long-eared hedgehog and many other animal species in the order Rodentia.

The results show that the structure of the papillae in the Japanese lesser flying squirrel is different from those of the four-toed hedgehog.

\section{Acknowledgements}

I am grateful to the staff of Osaka Municipal Tennoji Zoological Gardens and Gunma Safari Park for supplying the specimens.

\section{References}

1) Emura S: SEM study on the lingual papillae and their connective tissue cores of the black-tailed prairie dog (in Japanese). Medicine and Biology 2008a; 152:134-142.

2) Emura S: SEM study on the lingual papillae and their connective tissue cores of the capybara (in Japanese). Medicine and Biology 2008b; 152:386-393.

3) Emura S, Okumura, Chen H: Morphology of the lingual papillae in the bush-tailed kangaroo. Okajimas Folia Anat Jpn 2011; 88:121125

4) Emura S, Okumura, Chen H: Morphology of the lingual papillae in the Patagonian cavy. Okajimas Folia Anat Jpn 2014; 90:85-88.

5) Emura S, Tamada A, Hayakawa D, Chen H, Jamali M, Taguchi H, Shoumura S: SEM study on the dorsal lingual surface of the flying squirrel, Petaurista leucogenys. Ann Anat 1999; 181:495-498.

6) Emura S, Tamada A, Hayakawa D, Chen H, Shoumura S: SEM study on the dorsal lingual surface of the nutria, Myocastor coypus (in Japanese). Acta Anat Nippon 2001; 76:233-238.

7) Iwasaki S, Miyata K: Studies on the lingual dorsal epithelium of the guinea pig by scanning electron microscopy. Okajimas Folia Anat Jpn 1985; 61:423-436.

8) Iwasaki S, Miyata K, Kobayashi K: The surface structure of the dorsal epithelium of tongue in the mouse. Acta Anat Nippon 1987; 62:69-76.

9) Iwasaki S, Yoshizawa H, Kawahara I: Study by scanning electron microscopy of the morphogenesis of the three types of lingual papilla in the rat. Anat Rec 1997; 247:528-541.

10) Parchami A, Salimi M, Khosravi M: Tongue structure in the longeared hedgehog (Hemiechinus auritus): A scanning electron microscopic study. Vet Res Forum 2018; 9:205-209.

11) Silva MCP, Watanabe I, Kronka MC: Three-dimensional architecture of the connective tissue core and surface structures of the lingual papillae in the rabbit. Histol Histopath 2002; 17:455-461. 